\title{
Modification of Nanoclinoptilolite Zeolite with Hexadecyltrimethylammonium Surfactant as an Active Ingredient of Chromate-Selective Membrane Electrode
}

\author{
Alireza Nezamzadeh-Ejhieh and Gholamhosein Raja \\ Department of Chemistry, Islamic Azad University, Shahreza Branch, P.O. Box 311-86145, Shahreza, Isfahan, Iran \\ Correspondence should be addressed to Alireza Nezamzadeh-Ejhieh; arnezamzadeh@iaush.ac.ir
}

Received 10 June 2012; Accepted 16 August 2012

Academic Editor: Pedro Avila-Pérez

Copyright (C) 2013 A. Nezamzadeh-Ejhieh and G. Raja. This is an open access article distributed under the Creative Commons Attribution License, which permits unrestricted use, distribution, and reproduction in any medium, provided the original work is properly cited.

\begin{abstract}
A novel chromate selective PVC membrane electrode was constructed using a hexadecyltrimethylammonium-surfactant modified zeolite (SMZ) . Nano particles of an Iranian clinoptilolite zeolite were prepared by a ball-mill mechanical method and characterized by FT-IR, SEM and XRD. Best performance was exhibited at the membrane composition of SMZ: PVC: dioctyl phthalate (DOP) in the ratio of $4: 32: 64$. This membrane worked well over a wide concentration range from $5 \times 10^{-6}$ to $1.0 \times 10^{-2} \mathrm{~mol} \mathrm{~L}^{-1} \mathrm{of} \mathrm{CrO}_{4}{ }^{2-}$ with a Nernstian slope of $-29.38 \pm 0.29 \mathrm{mv}$ per decade of $\mathrm{CrO}_{4}{ }^{2-}$ concentration with detection limit of $2 \times 10^{-6} \mathrm{~mol} \mathrm{~L}^{-1}$ in a wide $\mathrm{pH}$ range of 6.8-10.7. The response time of the sensor is 5-10 s over a period of 2 months with good reproducibility. The selectivity coefficients of the proposed electrode towards various interfering ions were determined by FIM and SSM methods. The sensor was successfully used as indicator electrode in the potentiometric titration of $\mathrm{CrO}_{4}{ }^{2-}$ against $\mathrm{Pb}(\mathrm{II})$ and determination of chromium in an electroplating wastewater sample.
\end{abstract}

\section{Introduction}

Ion-selective electrodes (ISEs), because of their great interests regarding to their advantages, are used in a wide range of applications for the determination of ions and pharmaceuticals in aqueous environments. Comparing with other analytical methodologies, ion selective electrodes have some advantages such as: ease of preparation, relatively inexpensive, robust, durable, rapid response time, continuous monitoring, measure activity rather than concentration, do not affected by turbidity or color of sample and ideal for their use in the environmental studies [1]. As an important advantage, ISEs are known to be one of the few techniques that can measure both positive and negative ions depending on the nature of the ionophore.

Chromium is an element widely used in industrial activities such as chrome plating and electroplating, metal smelting and metallurgy to manufacture alloys, dyestuff industries, leather tanning, and wood treatment $[2,3]$. It exists as two major species, $\mathrm{Cr}$ (VI) and $\mathrm{Cr}$ (III) in natural waters and soils. $\mathrm{Cr}$ (III) is a stable and slightly soluble cation considered as an essential microelement [4], while $\mathrm{Cr}$ (VI) (as chromate) is highly water soluble and mobile anion, known as a toxic pollutant, with mutagenic and carcinogenic effects [5]. Due to the different toxicities of these two species, it is essential to determine hexavalent chromium rather than the total chromium concentration using a rapid and simple method that can be applied in industrial and environmental fields.

Potentiometric sensors for Cr (VI) analysis containing modifiers as nickel tris(1,10-bathophenantroline) [6], bis(acetylacetonato) cadmium (II) [7], cyclic amines [8], diaza crown ethers [9], rhodamine-B [10], or calix[4]arene [11] have been reported.

Zeolites, clinoptilolite is the most abundant of their natural category, are crystalline microporous aluminosilicates with very well-defined structures that consist of a framework 
formed by tetrahedra of $\mathrm{SiO}_{4}$ and $\mathrm{AlO}_{4}$. The isomorphous substitution of $\mathrm{Al}^{3+}$ for $\mathrm{Si}^{4+}$ in the tetrahedra results in a negative charge on the zeolite framework that can be balanced by exchangeable cations. Hence, zeolites can exchange cations but not anions. It has been demonstrated that the cationic surfactants have a great affinity to this negative charge. This property has been used to modify the external surface of the zeolites by adsorbing a cationic surfactant to improve its anion exchange capacity. The cationic surfactants that are most commonly used to modify zeolites are usually long alkyl chains with a quaternary ammonium group at one end of the chain such as hexadecyltrimethylammonium (HDTMA) bromide [12]. The sorption of a cationic surfactant on the external surface of a zeolite can be governed mainly by cationic exchange and hydrophobic interactions [13]. At a low surfactant loading, the surfactant cations are exchanged with the exchangeable cations of the zeolite until a monolayer of surfactant cations is formed at the external surface. At concentrations above the critical micelle concentration, a bilayer of surfactant molecules (admicelle) is attached to the external surface, where the outer layer of surfactant molecules is bound by hydrophobic interactions [14]. In this case a surfactant modified zeolite (SMZ) has produced whit changing the external surface charge of the zeolite from negative into positive which now displays anion exchange capacity.

Different properties were observed when immobilizing HDTMA on different substrate. Li et al. immobilized HDTMA onto the clinoptilolite for sorption of oxyanions [15]. Natural mordenite (NM) was used for adsorption of As (V) by Chutia et al. [16], and also zeolite $\mathrm{NaY}$ was used as substrate for ethylene adsorption by Patdhanagul et al. [17]. Zeolites have different cation exchange capacities (CECs) and external cation exchange capacities (ECECs) depending on their structures and $\mathrm{Si} / \mathrm{Al}$ ratio, where the latter case affects on the properties of the obtained SMZ. In addition, presence of bilayer on SMZ acts as an organic medium which affects in the hydrophilicity of obtained SMZ. Hence, we believe that the support on different SMZs has a major role in their adsorption behavior. Regarding different behaviors of HDTMA on different supports, we have constructed different selective electrodes based on SMZ modifier towards potentiometric determination of anions [18-21].

In this work, an Iranian natural clinoptilolite as an abundant zeolitic material in Iran was pretreated and changed to nanoparticles by mechanical ball milling process. After purification of the solid by reflux method, the purified nanoparticles were ion exchanged in HDTMA solution to yield SMZ. Then, the obtained SMZ was used as an active ingredient to modify PVC membrane. Constructing the electrode by this membrane shows better Nernstian behavior towards chromate anions rather than the other investigated anions. After the investigation of some experimental factors which affect the behavior of the proposed electrode, the electrode was used as indicator electrode in the potentiometric determination of chromate in a precipitation titration by $\mathrm{Pb}$ (II) solution. The statistical " $t$ " and " $g$ " tests were used to prove the validity of the results.

\section{Experimental}

2.1. Reagents. The natural zeolite used in this study originated from Semnan Province, in the north east of Iran. For membrane preparation, poly(vinyl chloride), dioctyl phthalate (DOP), tetrahydrofuran (THF), and hexadecyltrimethylammonium bromide (HDTMABr) were purchased from Aldrich chemicals and were used without further purification. All salts were purchased from Merck and used as received. Double-distilled deionized water was used throughout the experiments. The $\mathrm{pH}$ of the solutions was appropriately adjusted with $\mathrm{NaOH}$ or $\mathrm{HCl}$ solution as appropriate.

2.2. Preparation of the Nanozeolite and the SMZ. Natural clinoptilolite zeolite was mechanically pretreated, by crushing in an agate mortar and sieving in analytical sieves for the separation of $<100 \mu \mathrm{m}$ particle-size fractions. Nanoclinoptilolite was prepared using a planetary ball mill (PM100; Retsch Corporation). The milling can be down in two states including dry milling and wet milling. The milling conditions including the dry milling speed, the dry milling time, the ballto-powder ratio for dry milling and the wet milling speed, the wet milling time, the balls-to-powders ratio, and the waterto-powder ratio for wet milling should be optimized to reach size reduction and crystallinity retention. In this study, dry milling was applied. The milling speed, milling duration, and balls-to-powder ratio were $600 \mathrm{rpm}, 6 \mathrm{~h}$, and 4.0, respectively.

In order to remove the water-soluble impurities and also paramagnetic impurities especially, one entered during the ball milling step, the obtained nanoparticles were refluxed at $70^{\circ} \mathrm{C}$ for $8 \mathrm{~h}$ in distilled water while the suspension was stirred by a magnetic stirrer continuously. This was repeated five times to reach complete purification by observing the elimination of the adsorbed magnetic particles on magnet. In order to reach fixed water content, after filtration, washing, and drying of the powder, the purified material was stored in a desiccator over saturated sodium chloride solution for 2 weeks.

Surfactant modification of the zeolite was carried out using the surfactant, hexadecyltrimethylammonium bromide (HDTMABr), a cationic surfactant. A preweighed quantity of nanoclinoptilolite sample was mixed with HDTMABr solution in a $125 \mathrm{~mL}$ polyethylene bottles in a $1: 100$ (solid : liquid) ratio. The concentrations of HDTMABr solutions used for preparation of SMZ-1, SMZ-2, and SMZ-3 were 50,100, and $200 \mathrm{mM}$, respectively. The solution was agitated for $24 \mathrm{~h}$ at $150 \mathrm{rpm}$ on an orbital shaker and a temperature of $25^{\circ} \mathrm{C}$, a period shown sufficient to obtain sorption equilibrium. The mixture was then centrifuged at $3000 \mathrm{rpm}$ for $15 \mathrm{~min}$. The solution was then filtered, and the solid residue was washed with double-distilled water and airdried for $24 \mathrm{~h}$. The synthesized SMZ was then mechanically ground with a mortar and pestle to a fine particle size.

2.3. Characterization. Nano-particles of clinoptilolite were prepared using a planetary ball mill (PM100; Retsch Corporation). The zeolites were characterized by X-ray diffraction (XRD) by using a diffractometer Bruker, D8ADVANCE, 
$\mathrm{X}$-ray tube anode: $\mathrm{Cu}$, wavelength: $1.5406 \AA(\mathrm{Cu} \mathrm{K} \alpha$ radiation), Filter: Ni. The Fourier transform infrared (FT-IR) spectra of the samples were recorded at room temperature in $\mathrm{KBr}$ pellets using a Perkin Elmer FT-IR (Spectrum 65) spectrometer between 4000 and $400 \mathrm{~cm}^{-1}$ wavenumbers. To study probable changes of morphology for ground powders after ball milling, samples were subjected to SEM investigation (Seron technology, model: AIS2100).

2.4. Preparation of Electrodes. The general procedure to prepare the SMZ-PVC membrane was mixing of various amounts of the ionophore (SMZ) together with appropriate quantities of DOP (as plasticizer) and PVC to give a total mass of $100 \mathrm{mg}$ in $1.5 \mathrm{~mL}$ of THF. The optimum composition of the membrane was $32 \mathrm{mg}$ of powdered PVC, $64 \mathrm{mg}$ of DOP plasticizer, and $4 \mathrm{mg}$ of SMZ. These compounds were dissolved in $1.5 \mathrm{~mL}$ of THF. The resulting mixture was poured into a glass dish of $2 \mathrm{~cm}$ diameter. The solvent was slowly evaporated until an oily concentrated mixture was obtained. A Pyrex tube of $4 \mathrm{~mm}$ i. d. was dipped into the mixture for about $5 \mathrm{~s}$, so that a nontransparent membrane of $0.3 \mathrm{~mm}$ thickness was formed. The tube was then pulled out from the mixture and kept at room temperature for $24 \mathrm{~h}$. Then it was filled with internal filling solution $1.0 \times 10^{-2} \mathrm{M} \mathrm{Na}_{2} \mathrm{CrO}_{4} \cdot 4 \mathrm{H}_{2} \mathrm{O}$. The prepared electrodes were finally conditioned for $2 \mathrm{~h}$ by soaking in a $1.0 \times 10^{-2} \mathrm{M} \mathrm{Na}_{2} \mathrm{CrO}_{4} \cdot 4 \mathrm{H}_{2} \mathrm{O}$ solution. A silver-silver chloride wire was used as the internal reference electrode.

2.5. Potential Measurements. The potential measurements were carried out at $25 \pm 1^{\circ} \mathrm{C}$ with a Metrohm pH meter 691 . To prevent any transfer of ions to the measuring solution, the external reference electrode used was an $\mathrm{Ag} / \mathrm{AgCl}$ electrode shielded by an intermediate salt bridge compartment containing the background electrolyte. The cells for potential $(\mathrm{mV})$ measurement were of the following configuration:

$$
\begin{aligned}
& \mathrm{Ag} / \mathrm{AgCl}, \mathrm{KCl}(3 \mathrm{M}) \mathrm{|} \\
& \text { internal solution chromate }\left(1.0 \times 10^{-2} \mathrm{M}\right) \mid \\
& \text { electrode membrane | }
\end{aligned}
$$

test solution |

$\mathrm{Ag} / \mathrm{AgCl}, \mathrm{KCl}(3 \mathrm{M})$.

A small magnetic stirring bar and $20 \mathrm{~mL}$ of chromate solution were placed in a $50 \mathrm{~mL}$ beaker. The test solutions were constantly stirred by a magnetic stirrer. The electrodes were conditioned with chromate and thoroughly rinsed with double-distilled deionized water, and the surface of the ISE was washed between measurements to minimize electrode fouling. The chromate selective electrode and reference electrode were then inserted into the solution, and the potential difference was measured.

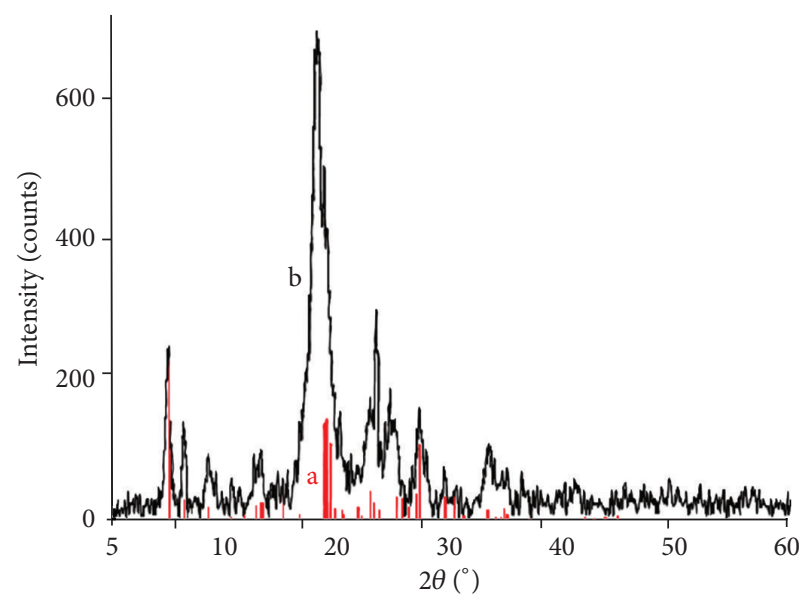

FIGURE 1: XRD patterns of (a) the reference pattern of clinoptilolite and (b) prepared zeolite nanoclinoptilolite.

\section{Results and Discussion}

\subsection{Characterization of Prepared Nanoclinoptilolite and SMZ}

3.1.1. X-Ray Diffraction Studies. The X-ray diffraction (XRD) patterns of reference clinoptilolite and prepared nanoclinoptilolite are shown in Figures 1(a) and 1(b), respectively. The XRD pattern of the reference clinoptilolite sample was selected from the manual library of the instrument which is in accordance with the JCPDS no. 39-1383. The lines and position remained intact that show a good agreement with the data of clinoptilolite in the literature [22]. Good agreement between the results shows that the original natural zeolite includes clinoptilolite structure as major component. XRD pattern also showed that the used zeolite tuffs include slight amounts of quartz $(3.5 \%)$ and cristobalite $(7.8 \%)$ phases as impurities. Presence of the broad lines in the XRD pattern of the prepared sample agrees with the formation of nanoparticles during the ball-milling process. So, we determined the average size of this sample using $\beta$, the excess of width line of the diffraction peak in radians, and $\theta$, the Bragg angle in degrees, and using the Debye-Scherrer formula:

$$
d=\frac{k \lambda}{\beta_{1 / 2}} \cos \theta,
$$

where $d$ is the mean crystallite diameter, $\lambda$ is the X-ray wavelength, $K$ is the Scherer's constant (0.89), $\beta_{1 / 2}$ is the full width at half maximum (FWHM) of the diffraction peaks and $\theta$ is the diffraction angle. The average particle sizes of prepared nanoclinoptilolite lays between 20 and $28 \mathrm{~nm}$.

3.1.2. FT-IR Studies. The FT-IR spectra of natural and modified zeolite samples covering the range from 400 to $4000 \mathrm{~cm}^{-1}$ were taken. FT-IR spectra obtained using $\mathrm{KBr}$ pellets of the unmodified clinoptilolite zeolite, the HDTMA surfactant, and the SMZ are presented in Figures 2(a), 2(b), and $2(\mathrm{c})$, respectively. Comparing the IR spectrum of the SMZ sample with others (Figure 2(c)) shows characteristic peaks at wavenumbers of $3016,2919,2849$, and $1483 \mathrm{~cm}^{-1}$ 


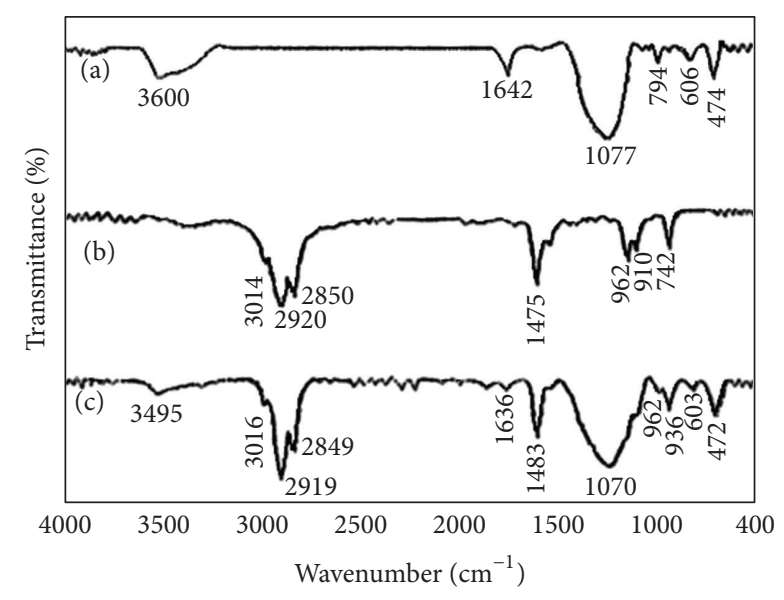

FIGURE 2: FT-IR patterns for (a) the prepared zeolite nanoclinoptilolite, (b) HDTMA and (c) SMZ.

which indicate the incorporation of HDTMA onto the zeolite surface. Although there are some slight shifts in the peaks position at each wavenumber in spectra of (a) and (c) in Figure 2, both of the patterns are nearly the same, showing unchanging of the zeolite structure during the HDTMA loading. Particularly, the presence of peaks at 3016, 2919, 2849 and $1483 \mathrm{~cm}^{-1}$ in the SMZ spectrum (related to $\mathrm{C}-\mathrm{H}$, $\mathrm{C}-\mathrm{C}$ and $\mathrm{N}-\mathrm{C}$ vibrations in the surfactants, resp.), that are absent in the clinoptilolite spectrum, confirms the loading of HDTMA onto the zeolite surface.

3.1.3. Surface Morphology Studies. Some of the SEM images of nanoclinoptilolite and the obtained SMZ are shown in Figure 3. SEM images indicated that almost in all samples, zeolite powder with particles size less than $100 \mathrm{~nm}$ can be recognized as a separated particle or in the form of larger agglomerates. Moreover most particles have lost their initial layered shape and converted into spherical, elliptical, or irregular shapes. By careful considerations of SEM images, some crystals with sharp edges and clean surfaces were observed; which are about $100-200 \mathrm{~nm}$ in size. Therefore, it can be concluded that careful selection of milling conditions may result in production of nanoclinoptilolite zeolite with desirable crystalline structure. Nevertheless, mechanical production of zeolitic nanoparticles by means of planetary ball mills may also reduce the zeolite crystallinity.

\subsection{Potentiometric Experiments}

3.2.1. Theoretical and Membrane Composition Investigations. Anionic properties can easily be imparted on the zeolitic surface using the surface modification by surfactants. When the initial concentration of the sorbed surfactant molecules is less than its critical micelle concentration (CMC), a monolayer of surfactant molecules forms on the zeolite surface. At concentration greater than the CMC and when enough surfactant exists in the system, the sorbed surfactant molecules form bilayers which induces positively charged functional groups to orient toward the solution; thus creating sorption sites for anions was performed [23-28]. The surfactant molecules form bilayers on zeolite external surfaces with the lower layer held by electrostatic interaction between the negatively charged zeolite surface and the positively charged surfactant head groups while the upper layer is bound to the lower layer by hydrophobic forces between the surfactant tail groups in both layers [29]. Sorption of inorganic anions on cationic surfactant modified zeolite has been attributed to the formation of a surface-anion complex [30]. The positively charged head groups are balanced by counter ions, and the sorption or exchange of other anionic constituents involves the replacement of weakly held counter ions by more strongly held counter ions.

Preliminary experiments showed that when SMZ was mixed with a solution containing chromate anion, the concentration of chromate in the remaining solution was decreased. These investigations confirm that the double layers of surfactant on the surface of zeolite have been formed and SMZ can adsorb anions. Adsorption of colored anions such as chromate, dichromate, and permanganate onto the surface of the SMZ causes colored surfaces and this color is stable even by rinsing the surface for several times while if the raw zeolite was added to this colored anions solution, the anion adsorption separated with rinse easily and color intensity on surface of zeolite decreases extremely. This method was reported as the easiest and fastest way to confirmation for produce of SMZ in previous works $[21,31]$.

In this work, we were interested in investigating the possibility of the use of surfactant modified zeolite, formulated as SMZ, as an ionophore in PVC-based membranes for chromate ion. Thus, in preliminary studies, SMZ was used as an ionophore to prepare PVC membrane ion-selective electrodes for a wide variety of anions. The potential responses of various anion-selective electrodes based on SMZ used are shown in Figure 4 and Table 1. As seen, with the exception of chromate ion, all anions tested show negligible responses in the concentration range of $1.0 \times 10^{-7}-1.0 \times$ $10^{-1} \mathrm{~mol} \mathrm{~L}^{-1}$. Noteworthy, among these anions, chromate shows a higher potential response at higher concentrations. Hence, the modified nanoclinoptilolite with HDTMA was used as an ionophore for construction of a potentiometric sensor for this anion. Since $\mathrm{CrO}_{4}{ }^{2-}$ is the predominant form of chromium species at the conditions used in this work, the sorption mechanism can be shown by the following reaction:

$$
2\left(\mathrm{R}_{4} \mathrm{~N}^{+} \text {in } \mathrm{SMZ}\right)+\mathrm{CrO}_{4}{ }^{2-} \longleftrightarrow\left(\mathrm{R}_{4} \mathrm{~N}\right)_{2} \mathrm{CrO}_{4}
$$

where, $\mathrm{R}_{4} \mathrm{~N}^{+}$represents the anion-exchange sites of HDTMA surfactant on SMZ. Thus, when the SMZ-PVC membrane electrode is immersed in the chromate solutions, an anion exchange reaction occurs between the anion on the electrode surface $\left(\mathrm{Br}^{-}\right)$and $\mathrm{CrO}_{4}{ }^{2-}$ in the solution.

So, the electrode was investigated in further detail. Secondly, the amount of SMZ modifier was optimized. The responses of the electrodes to several SMZ compositions are presented in Table 2. It is clear that only the electrode containing 4\% SMZ prepared from clinoptilolite at $100 \mathrm{mM}$ HDTMA solution shows Nernstian behavior. This electrode 
TABLE 1: Potentiometric response of the SMZ-PVC electrode toward different anions $(n=5)$ with each electrode conditioned in a $0.01 \mathrm{M}$ solution of the corresponding anion for $2 \mathrm{~h}$ at 25 (membrane includes $4 \% \mathrm{SMZ}$ ).

\begin{tabular}{lccc}
\hline Anion & Slope $(\mathrm{mV} \cdot$ decade & \\
\hline Benzoate & $-35.0 \pm 1.1$ & $r^{2}$ & Linear range $(-\log C)$ \\
$\mathrm{ClO}_{3}{ }^{-}$ & $-36.3 \pm 1.3$ & $0.9705 \pm 0.0137$ & $2-4$ \\
$\mathrm{CN}^{-}$ & $-46.4 \pm 1.4$ & $0.9975 \pm 0.0018$ & $1-4$ \\
$\mathrm{I}^{-}$ & $-40.0 \pm 0.9$ & $0.9936 \pm 0.0113$ & $3-5$ \\
$\mathrm{NO}_{3}{ }^{-}$ & $-19.9 \pm 0.5$ & $0.9980 \pm 0.0005$ & $1-5$ \\
$\mathrm{C}_{2} \mathrm{O}_{4}{ }^{2-}$ & $-43.5 \pm 0.6$ & $0.9896 \pm 0.0136$ & $1-4$ \\
$\mathrm{ClO}_{4}{ }^{-}$ & $-41.8 \pm 1.7$ & $0.9811 \pm 0.0072$ & $2-4$ \\
$\mathrm{CrO}_{4}{ }^{2-}$ & $-29.0 \pm 0.6$ & $0.9910 \pm 0.0053$ & $1-4$ \\
\hline
\end{tabular}

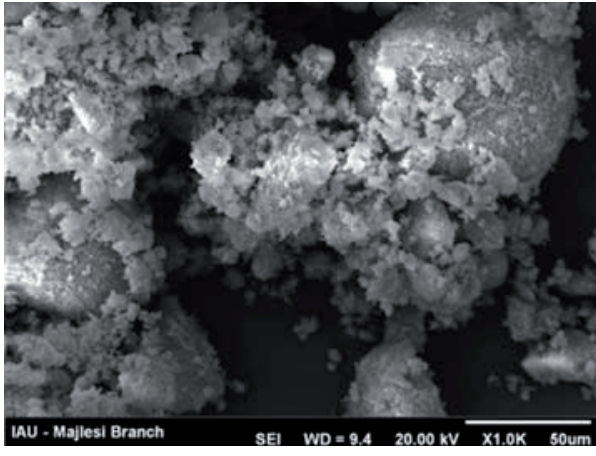

(a)

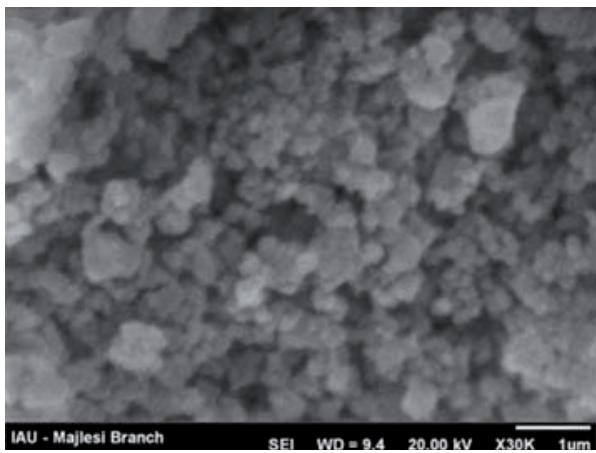

(c)

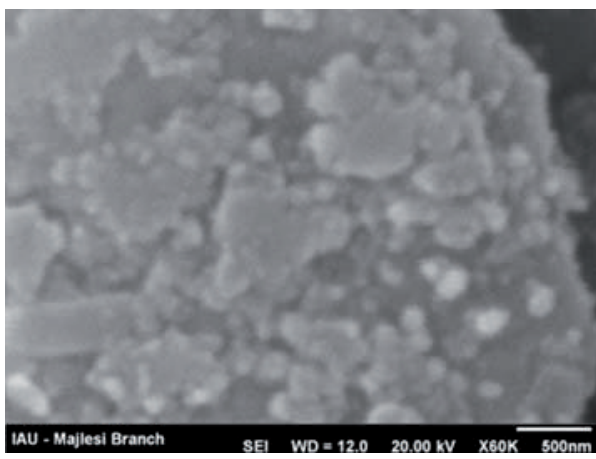

(e)

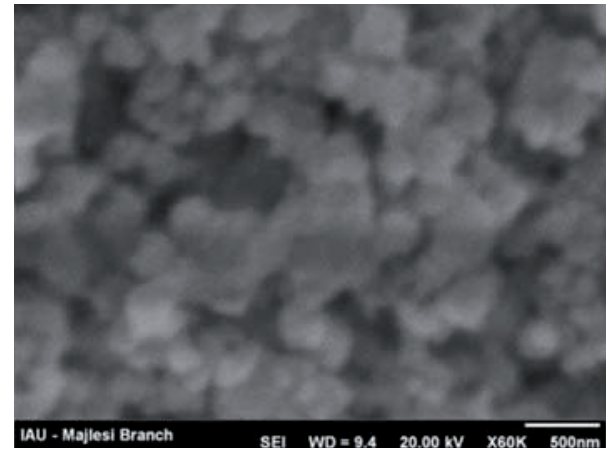

(b)

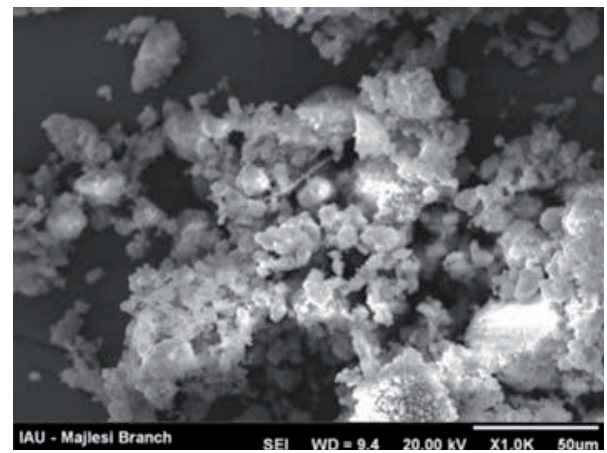

(d)

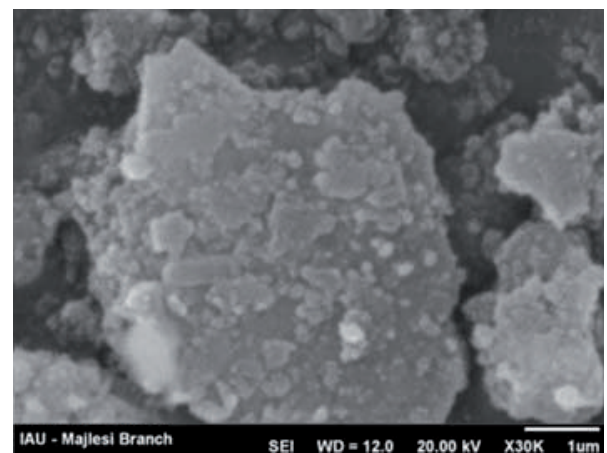

(f)

FIGURE 3: SEM images of nano-clinoptilolite $(a-c)$ and SMZ (d-f). 
TABLE 2: Optimization of the modifier percentage in chromate-selective electrode based on SMZ at $25^{\circ} \mathrm{C}(n=5)$.

\begin{tabular}{|c|c|c|}
\hline Electrode & Modifier percentage & Slope $\left(\mathrm{mV} \cdot \mathrm{decade}^{-1}\right)(n=5)$ \\
\hline $\mathrm{A}$ & 4\% (nanoclinoptilolite +50 mM HDTMA) & $-47.7 \pm 1.3$ \\
\hline B & $4 \%$ (nanoclinoptilolite +100 mM HDTMA) & $-29.2 \pm 1.4$ \\
\hline $\mathrm{C}$ & $4 \%$ (nanoclinoptilolite +200 mM HDTMA) & $-38.9 \pm 0.6$ \\
\hline
\end{tabular}

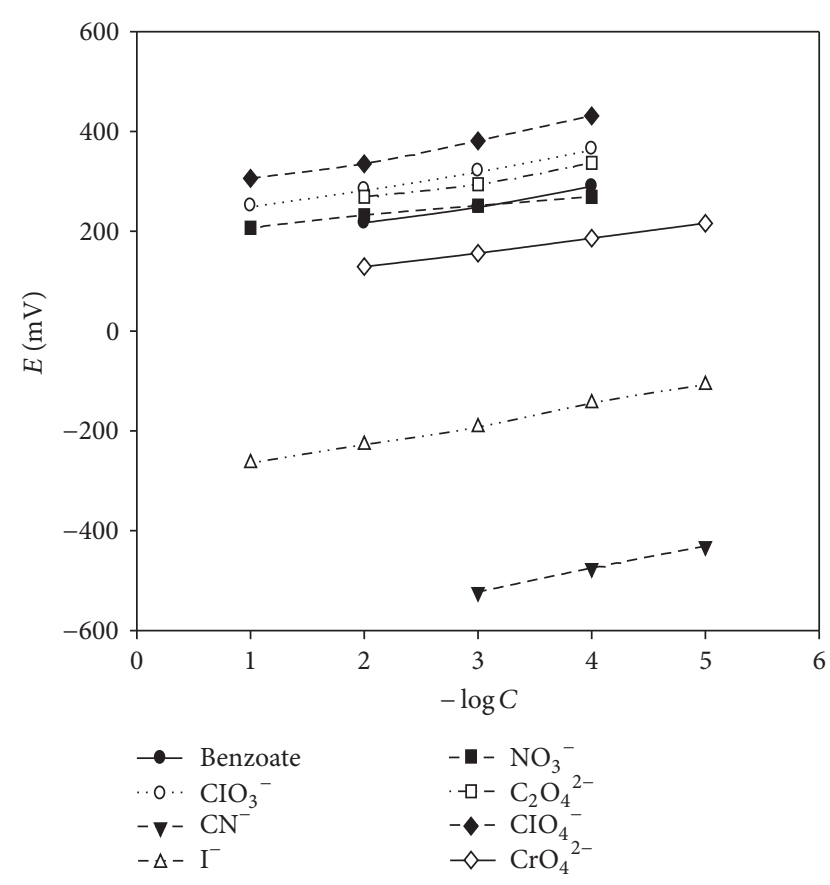

FIGURE 4: A schematic diagram of the electrode response to various anions.

also showed good linear response within the concentration range of $1.0 \times 10^{-5}$ to $1.0 \times 10^{-2} \mathrm{~mol} \mathrm{~L}^{-1}$ chromate. In the $50 \mathrm{mmol} \mathrm{L}^{-1}$ HDTMA solution, a bilayer may be formed partially at the zeolite surface, and the obtained SMZ is not suitable for $\mathrm{CrO}_{4}{ }^{2-}$ adsorption (Table 2A). The electrode $\mathrm{C}$ in Table 2, prepared in a $200 \mathrm{mmol} \mathrm{L}^{-1}$ HDTMA solution, does not exhibit Nernstian behavior. In this case, a partial bilayer may be loaded on the zeolite surface. Consequently, the obtained SMZ does not respond appropriately to $\mathrm{CrO}_{4}{ }^{2-}$. These observations are in accordance with our previous works [18-21] and also with results for antimonate sorption [32]. Wingenfelder et al. found when the external CEC was almost twofold, the zeolite absorbed $>98 \%$ of the initial HDTMA in solution. When the applied HDTMA concentrations were more than twice the concentration of the external CEC, the zeolite absorbed $84 \%$ of the initial HDTMA concentration. Sullivan et al. upon the FT-Raman spectroscopy and batch sorption methods showed the orientation of surfactant depends on the surfactant's amount that was adsorbed onto surface of zeolites (Figure 5). For example, if concentration of surfactant is lower than the certain value, interaction between surfactant and zeolite will be horizontal; it means that, at lower loadings, the sorbed HDTMA tail groups tended to have more disorder, similar to solution monomers shown in

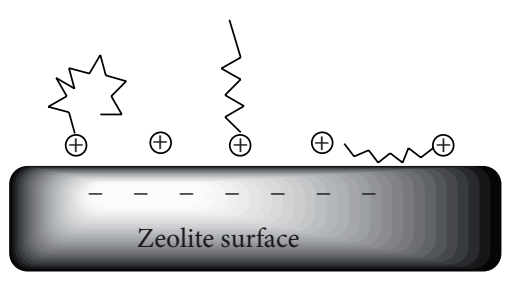

(a)

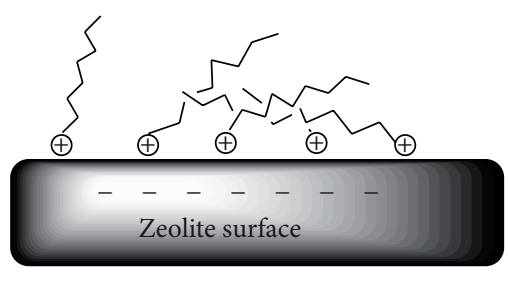

(b)

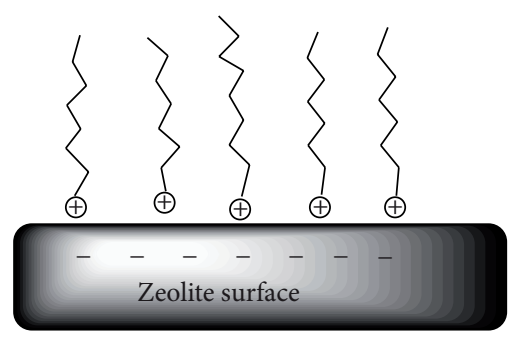

(c)

FIGURE 5: Various orientations of surfactant molecules on zeolite surface zeolite surface (a) lower coverage monolayer, (b) midcoverage monolayer, and (c) higher coverage monolayer.

Figures 5(a) and 5(b), but if concentration of surfactant is appropriate, interaction of them will be vertical, and in this situation we have the highest order, shown in Figure 5(c) [33].

The response properties of ion-selective electrodes based on ionophore are strongly influenced by the membrane composition, especially ionic sites $[34,35]$. In the case of ISEs based on neutral carriers, ionic sites with a charge sign opposite to that of the primary ions are necessary for obtaining a Nernstian response, to decrease the membrane resistance, reduce the counter-ion interferences, and improve the detection limit and optimization of selectivity. In ISEs based on the electrically charged carriers, on the other hand, the use of ionic sites with the same charge sign as the primary ions can significantly improve the response properties and selectivity of the sensor. Thus, the influence of the membrane composition and amount of SMZ as an ionophore on the potential response of the chromate sensor was investigated. 
TABLE 3: Effect of SMZ-PVC membrane composition on the potentiometric behavior of the chromate-selective electrode $(n=5)$ at $25^{\circ} \mathrm{C}$.

\begin{tabular}{lcccccc}
\hline No. & PVC\% & SMZ\% & DOP\% & Slope $\left(\mathrm{mV} \cdot\right.$ decad $\left.^{-1}\right)$ & $r^{2}$ & Linear range $(-\log C)$ \\
\hline 1 & 32.7 & 2 & 65.3 & $40.1 \pm 0.7$ & $0.9822 \pm 0.0010$ & $2-5$ \\
2 & 32 & 4 & 64 & $29.9 \pm 0.9$ & $0.9944 \pm 0.0035$ & $2-5$ \\
3 & 31.3 & 6 & 62.7 & $16.4 \pm 1.3$ & $0.9865 \pm 0.0019$ & $2-4$ \\
4 & 30 & 10 & 60 & $20.3 \pm 0.6$ & $0.9901 \pm 0.0058$ & $2-4$ \\
\hline
\end{tabular}

The effect of the membrane composition on the potentiometric response of the electrodes was investigated by varying the proportions of the ionophore (SMZ), plasticizer (DOP), and PVC. Table 3 presents the compositions of several typical membranes, along with their potentiometric response characteristics. The potential response of all the SMZ-PVC electrodes was studied in the concentration covering the range of $1 \times 10^{-7}-1 \times 10^{-1} \mathrm{~mol} \mathrm{~L}^{-1}$ chromate. The results indicate that the electrode comprised of $4 \% \mathrm{SMZ}, 32 \% \mathrm{PVC}$, and $64 \%$ DOP is suitable and the electrode exhibited a Nernstian response with a small standard deviation (membrane no. 2, Table 3). Thus, this membrane composition (optimized electrode) was used in the next experiments.

The performance characteristics of the investigated electrodes were studied as a function of conditioning times. For this purpose, the electrode was soaked in $1.0 \times 10^{-2} \mathrm{~mol} \mathrm{~L}^{-1}$ chromate solution for different intervals, and then the effect of soaking on the calibration graph slope was measured. Table 4 presents the results of investigating conditioning times. The results show that the best Nernstian response, combined with a dynamic range, was obtained at $2 \mathrm{~h}$. Hence, this time was employed as the conditioning time in later studies.

3.2.2. Effect of $p H$. In the aqueous phase, chromate exists in different ionic forms $\left(\mathrm{HCrO}_{4}{ }^{-}, \mathrm{Cr}_{2} \mathrm{O}_{7}{ }^{2-}, \mathrm{CrO}_{4}{ }^{2-}, \mathrm{HCr}_{2} \mathrm{O}_{7}{ }^{-}\right)$. The distribution of $\mathrm{Cr}$ (VI) species is dependent on both the total concentration of $\mathrm{Cr}(\mathrm{VI})$ and $\mathrm{pH}$ of the equilibrium solution. The following equations describe the distribution of chromium species in aqueous solution [36]:

$$
\begin{gathered}
\mathrm{H}_{2} \mathrm{CrO}_{4} \longleftrightarrow \mathrm{HCrO}_{4}{ }^{-}+\mathrm{H}^{+}, \\
\mathrm{HCrO}_{4}{ }^{-} \longleftrightarrow \mathrm{CrO}_{4}{ }^{2-}+\mathrm{H}^{+}, \\
2 \mathrm{HCrO}_{4}{ }^{-} \longleftrightarrow \mathrm{Cr}_{2} \mathrm{O}_{7}{ }^{2-}+\mathrm{H}_{2} \mathrm{O}, \\
\mathrm{HCr}_{2} \mathrm{O}_{7}{ }^{1-} \longleftrightarrow \mathrm{Cr}_{2} \mathrm{O}_{7}{ }^{2-}+\mathrm{H}^{+}
\end{gathered}
$$

The $\mathrm{CrO}_{4}{ }^{2-}$ anion prevails in basic or slightly acidic solution while the $\mathrm{Cr}_{2} \mathrm{O}_{7}{ }^{2-}$ anion is dominant in acidic $\mathrm{Cr}$ (VI) aqueous solution [37]:

$$
\begin{aligned}
\mathrm{CrO}_{4}{ }^{2-}(\mathrm{pH}>6.5) & \longleftrightarrow \mathrm{HCrO}_{4}^{-}(\mathrm{pH} 4-6) \\
& \longleftrightarrow \mathrm{Cr}_{2} \mathrm{O}_{7}^{2-}(\mathrm{pH}<4)
\end{aligned}
$$

The $\mathrm{pH}$ of aqueous $10^{-4} \mathrm{~mol} \mathrm{~L}^{-1} \mathrm{CrO}_{4}{ }^{2-}$ solution was altered by dilute $\mathrm{NaOH}$ or $\mathrm{HCl}$ solutions, and the potential of the solutions was monitored. The $\mathrm{pH}$ dependence of the
TABLE 4: Conditioning time for the SMZ-PVC membrane electrode based on $4 \% \operatorname{SMZ}(-\log C=5-2 ; n=5)$ at $25^{\circ} \mathrm{C}$.

\begin{tabular}{lcc}
\hline$t(\mathrm{~h})$ & Slope $\left(\mathrm{mV} \cdot\right.$ decade $\left.^{-1}\right)$ & $r^{2}$ \\
\hline 2 & $29.4 \pm 1.5$ & $0.9927 \pm 0.0069$ \\
4 & $20.6 \pm 1.2$ & $0.9682 \pm 0.0258$ \\
7 & $45.4 \pm 0.74$ & $0.9790 \pm 0.0022$ \\
10 & $21.3 \pm 1.0$ & $0.9841 \pm 0.0071$ \\
12 & $16.7 \pm 1.4$ & $0.9746 \pm 0.0135$ \\
16 & $22.3 \pm 0.84$ & $0.9768 \pm 0.0110$ \\
24 & $32.1 \pm 2.2$ & $0.9530 \pm 0.0110$ \\
48 & $14.4 \pm 0.63$ & $0.9748 \pm 0.0160$ \\
\hline
\end{tabular}

potential response of the proposed electrode in the $\mathrm{pH}$ range of 1-12 was tested, and the results are shown in Figure 6. As can be seen, the potential response remains almost constant over the $\mathrm{pH}$ range of $6.8-10.7 . \mathrm{pH}$ values decrease in the measurable concentration of chromate and formation of dichromate and polychromate [38], to which the sensor does not appear to respond in Nernstian manner. For studying the effect of $\mathrm{pH}$, another method was used as follows: different series of solutions covering the concentration range from $1 \times 10^{-5}$ to $1 \times 10^{-2} \mathrm{~mol} \mathrm{~L}^{-1}$ were made, and the $\mathrm{pH}$ of each set was kept constant value. Results which are shown in Table 5 show the good Nernstian behavior for $\mathrm{pH}=8$. Subsequently, in our investigations, the solution $\mathrm{pH}$ values were adjusted to 8 when required. More acidic $\mathrm{pH}$ values affected the potential response probably due to partial destruction of the zeolite lattice, which occurs in acidic media [39], and interference from $\mathrm{Cl}^{-}$. Zeolite minerals decompose in acids and form gels or insoluble silica depending on the structure of the zeolite and $\mathrm{Si} / \mathrm{Al}$ ratio [21]. Conversely, in high $\mathrm{pH}$ media, the interference by a high concentration of $\mathrm{OH}^{-}$ions induces an increased electrode response [21]. In addition to the dealumination of zeolites in acidic media, many of the zeolites, although stable under the particular conditions of their synthesis, may undergo conversion to different species with time [21]. In these conditions, SMZ may decompose due to the different external CEC values of clinoptilolite and the converted materials. In highly acidic and basic media, the electrode may respond to monovalent $\mathrm{Cl}^{-}$and $\mathrm{OH}^{-}$anion additions to the chromate, and due to the their different charges and hence different slopes (according to Nernst equation for monovalent $\mathrm{Cl}^{-}$and $\mathrm{OH}^{-}$anions) with chromate, a potential change occurs. In addition to these problems, chromate protonation that occurs with a decrease in $\mathrm{pH}$ must be taken into consideration. Therefore, a $\mathrm{pH}$ of 8 was selected as the optimal value. 
TABLE 5: Effect of $\mathrm{pH}$ on Nernstian behavior of the chromateselective electrode $(-\log C=5-2 ; n=5)$ at $25^{\circ} \mathrm{C}$.

\begin{tabular}{lcc}
\hline $\mathrm{pH}$ & Slope $\left(\mathrm{mV} \cdot\right.$ decad $\left.^{-1}\right)$ & $r^{2}$ \\
\hline 2 & $33.9 \pm 1.0$ & $0.9880 \pm 0.0171$ \\
4 & $41.4 \pm 1.3$ & $0.9811 \pm 0.0116$ \\
6 & $43.7 \pm 0.8$ & $0.9955 \pm 0.0073$ \\
7 & $29.8 \pm 0.6$ & $0.9905 \pm 0.0054$ \\
8 & $29.3 \pm 0.4$ & $0.9940 \pm 0.0041$ \\
9 & $28.6 \pm 0.9$ & $0.9900 \pm 0.0057$ \\
10 & $29.5 \pm 0.3$ & $0.9926 \pm 0.0049$ \\
11 & $19.3 \pm 1.6$ & $0.9854 \pm 0.0123$ \\
\hline
\end{tabular}

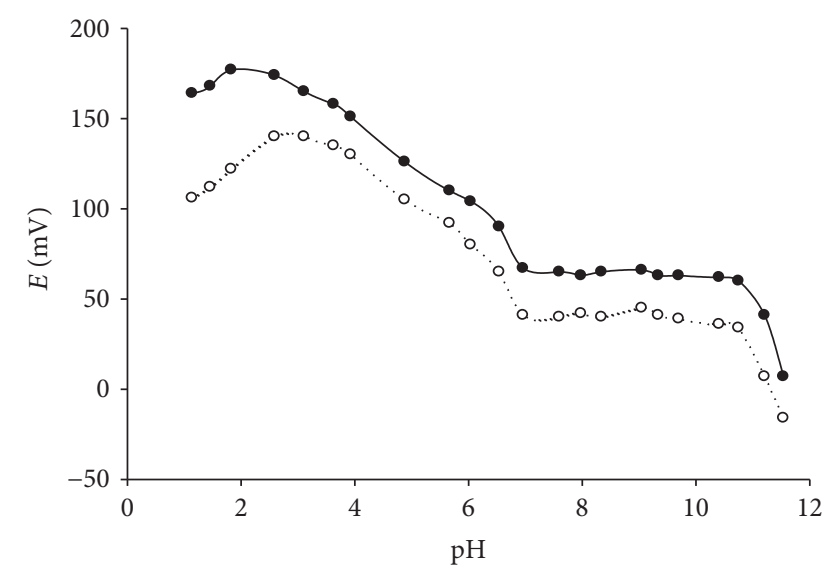

FIGURE 6: Influence of $\mathrm{pH}$ on the potential response of the chromateselective electrode to $1.0 \times 10^{-4} \mathrm{~mol} \mathrm{~L}^{-1}$ chromate.

3.2.3. Effect of Temperature. To study the thermal stability of the sensors, they constructed at different test solution temperatures of $25,30,35,40,45,50$, and $60^{\circ} \mathrm{C}$. The results which are shown in Table 6 show the electrode exhibited good Nernstian behavior in the range of $25-40^{\circ} \mathrm{C}$. The Nernstian and experimental slope values at each temperature were compared statistically by $t$-test [40], showing conformity of the slopes for 5 replicates. On the other hand, the smaller experimental $t$-values than its critical value in the $25-40^{\circ} \mathrm{C}$ temperature range show systematic errors affect the response the proposed electrode. The results prove the validation of the obtained results with the expected values in the temperature range of $25-40^{\circ} \mathrm{C}$. However, at temperatures higher than $40^{\circ} \mathrm{C}$ the slopes show a significant deviation from the theoretical values, because of the presence of the systematic errors in the responses. The main factors for this deviation can be considered as the phase boundary equilibrium at the gel layer test solution interface which is disturbed by the thermal agitation of the solution [21] and may also be related to surfactant desorption from the SMZ and destruction of the electrode surface at higher temperatures.

3.2.4. Response Time. Generally, dynamic response time is an important factor for any sensor. The critical EMF response of the electrode was assessed according to IUPAC recommendations [42]. The average time required for the mentioned

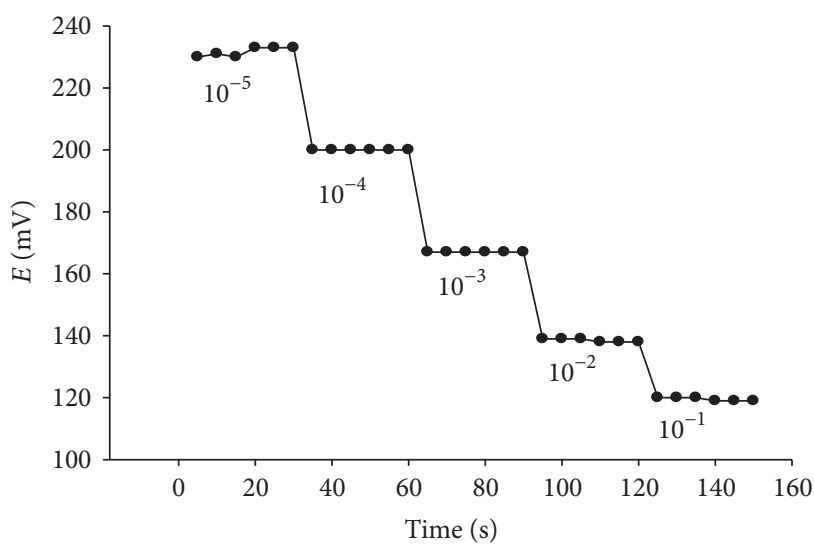

FIGURE 7: Response time of the SMZ-PVC to different concentration of chromate $(\mathrm{pH}=8)$ in the range of $1 \times 10^{-5}$ to $1 \times 10^{-1} \mathrm{~mol} \mathrm{~L}^{-1}$.

electrode to reach a potential within $\pm 1 \mathrm{mV}$ of the final equilibrium value after successive immersion of chromate ion solutions, each having a 10-fold difference in concentration, was investigated. The measurements of potential versus time were carried out with chromate solutions from lower $1.0 \times$ $10^{-5} \mathrm{~mol} \mathrm{~L}^{-1}$ to higher $1.0 \times 10^{-1} \mathrm{~mol} \mathrm{~L}^{-1}$ concentrations (Figure 7). The electrode yielded steady potentials within $5-10 \mathrm{~s}$. The potentials remained constant for about $150 \mathrm{~s}$. The response time increased to $10 \mathrm{~s}$ when the concentration was lowered to $1.0 \times 10^{-5} \mathrm{~mol} \mathrm{~L}^{-1}$ because of the longer equilibration time, whereas higher concentrations have response times of less than $5 \mathrm{~s}$.

3.2.5. Potentiometric Selectivity. Interfering of concomitants on the response of the analytical methods is the most limiting factor of these methods. The most important characteristic of any ion-selective electrode is its response for the primary ion in the presence of other anions in solution, which is expressed in terms of the potentiometric selectivity coefficient $\left(k_{\mathrm{A}, \mathrm{B}}^{\mathrm{pot}}\right)$. Potentiometric selectivity coefficients were determined by the fixed interference method (FIM) at fixed concentration of interfering ions and varying amounts of the primary ion [43]. This method measured the potential of the electrode in a series of solutions containing a fixed activity of the interfering anion $a_{\mathrm{B}}\left(0.1 \mathrm{~mol} \mathrm{~L}^{-1}\right)$ and varied concentrations of chromate in the range of $5 \times 10^{-6}$ to $1 \times 10^{-2} \mathrm{~mol} \mathrm{~L}^{-1}$. The potential values obtained are plotted versus the activity of the primary ion. The intersection of the extrapolation of the linear portions of this curve will indicate the value of $a_{\mathrm{A}}$ which is to be used to calculate $k_{\mathrm{A}, \mathrm{B}}^{\text {pot }}$ from the equation (Figure 8):

$$
\begin{aligned}
\log k_{\mathrm{A}, \mathrm{B}}{ }^{\mathrm{pot}}= & E_{2}-\frac{E_{1}}{2.303 \mathrm{RT} / Z_{\mathrm{A}} F} \\
& +\left(1-\frac{Z_{\mathrm{A}}}{Z_{B}}\right) \log \alpha_{\mathrm{A}},
\end{aligned}
$$

where both $Z_{\mathrm{A}}$ and $Z_{\mathrm{B}}$ have the same signs, positive or negative, and are the valence of primary and interfering ions, respectively. 
TABLE 6: Effect of temperature on the optimized SMZ-PVC electrode behavior $(n=5)$.

\begin{tabular}{lccc}
\hline Temperature $\left({ }^{\circ} \mathrm{C}\right)$ & Nernstian slope $\left(\mathrm{mV} \cdot\right.$ decade $\left.^{-1}\right)$ & Mean of exp. slope $(n=5)\left(\mathrm{mV} \cdot\right.$ decade $\left.^{-1}\right)$ & $t_{\text {exp }}{ }^{a}$ \\
\hline 25 & 29.6 & $29.7 \pm 0.4$ & 0.59 \\
30 & 30.1 & $30.3 \pm 0.7$ & 0.69 \\
35 & 30.6 & $30.4 \pm 1.3$ & 0.34 \\
40 & 31.1 & $31.4 \pm 0.9$ & 0.71 \\
45 & 31.6 & $15.6 \pm 2.6$ & 13.63 \\
50 & 32.1 & $12.9 \pm 0.5$ & 93.50 \\
60 & 33.1 & $18.2 \pm 2.0$ & 16.88 \\
\hline
\end{tabular}

${ }^{\mathrm{a}} t_{0.05,4}=2.78$ [40].

The selectivities of electrodes were also investigated by the separate solution method [43] $\left(a_{\mathrm{A}}=a_{\mathrm{B}}=10^{-2} \mathrm{~mol} \mathrm{~L}^{-1}\right)$ in the way that the potential of a cell comprising an ion-selective electrode and a reference electrode is measured with each of two separate solutions, one containing the ion $\mathrm{A}$ at the activity $a_{\mathrm{A}}$ (but no $\mathrm{B}$ ) and the other containing the ion $\mathrm{B}$ at the same activity $a_{\mathrm{B}}=a_{\mathrm{A}}$ (but no $\mathrm{A}$ ). If the measured values are $E_{1}$ and $E_{2}$, respectively, the value of $k_{\mathrm{A}, \mathrm{B}}{ }^{\text {pot }}$ can be calculated from the equation:

$$
\log k_{\mathrm{A}, \mathrm{B}}^{\text {pot }}=\frac{\alpha_{\mathrm{A}}}{\alpha_{\mathrm{B}}{ }^{\left(Z_{\mathrm{a}} / Z_{\mathrm{b}}\right)}} .
$$

In Table 7 , the selectivity coefficients and response characteristics of the SMZ-PVC electrode are compared with the other chromate selective electrodes. According to the results, selectivity shows deviation from Hofmeister series. The reason the selectivity coefficients of this electrode do not comply with the Hofmeister series, and show an antiHofmeister behavior, is thought to be due to the possible interaction of the anions with HDTMA [44]. Depending on the mode of interaction with cationic surfactants, anions are classified into four classes [44]. Most "Hofmeister" anions do not bind strongly on the head groups and behave as typical counter ions $\left(\mathrm{OH}^{-}, \mathrm{CH}_{3} \mathrm{COO}^{-}\right.$, and $\left.\mathrm{HCOO}^{-}\right)$. Class II ions are usually large complex ions with large polarizabilities, which form water-insoluble ion pairs with the amine-based surfactants $\left(\mathrm{I}^{-}, \mathrm{SCN}^{-}\right.$, and $\left.\mathrm{ClO}_{4}{ }^{-}\right)$. Class III consists of complex anions containing transition metal ions, which form covalent bonds with the amine-head groups and also between themselves through oxygen bridges. Finally, class IV consists of a number of hydrophobic organic anions (benzoate, salicylate, tosylate), which partly dissolve in the palisade layer of the surfactant. Hofmeister anions also affect the size and shape of micelles of cationic surfactants and their phase diagrams regarding their hydrated sizes [44]. It often happens that several different anions compete for a cationic micellar surface.

According to the previous discussion, different anions have different interactions with head group and the chain of HDTMA surfactant, which in turn cause a deviation from Hofmeister series.

3.2.6. Life-Time Study. Lifetime or durability of ISEs is one of the important factors in deciding the applicability of ISE. The lifetime of electrodes based on ionophores in

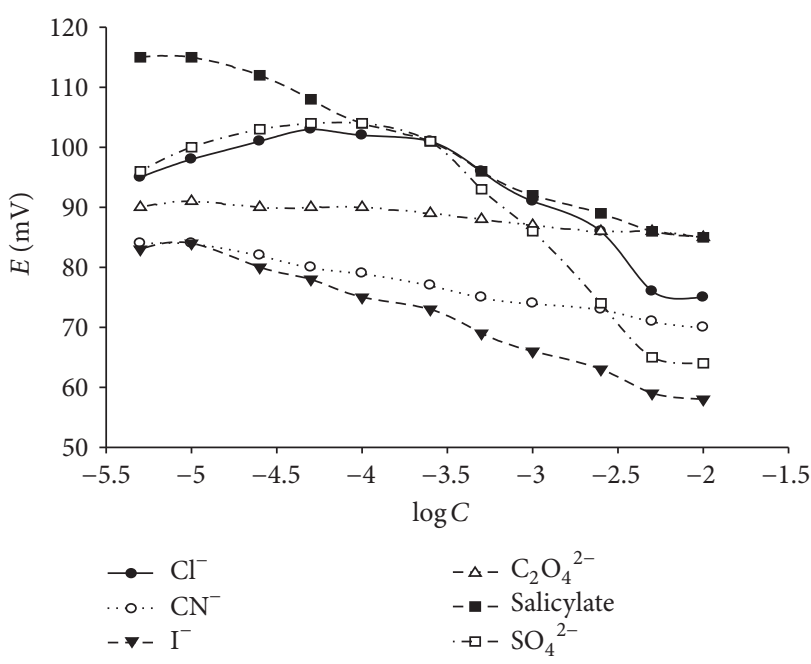

FIgURE 8: A schematic diagram of the electrode response to various interferences with FIM method.

solvent polymeric membranes depends on the distribution coefficient of the ionophore and the plasticizer between the aqueous and membrane phases [43]. Hence, the lifetime of electrodes must depend on the components of the solution and the measured specimens with electrodes. Durability of the membrane was tested by monitoring the change in the slope and linear response range with time. The lifetime of the electrode was determined by reading its potentials and plotting the calibration curves for a period of 2 months. The results of the studies revealed a very slight gradual decrease in the slope of the electrode after 2 months. This negative effect of soaking is attributed to the leaching of the ionophore and plasticizer to the bathing solution which is related to the distribution equilibria and diffusion rates. Another explanation can be related to the penetration of the water molecules from the bathing solution to the membrane and consequently slow solvation of the lipophilic salts in situ, so they are slowly leached out and limit the electrode life [45].

3.2.7. Response Characteristics of the Electrode. Using the optimized membrane composition and conditions described previosly, the critical response characteristics of the electrode were evaluated according to IUPAC recommendations [42]. 
TABLE 7: Comparison of some potentiometric characteristics of the chromate ISE described in this paper with previously published reports.

\begin{tabular}{|c|c|c|c|c|}
\hline \multirow{2}{*}{ Interference ions } & \multicolumn{2}{|c|}{ Log $k$ values in the references } & \multicolumn{2}{|c|}{ This paper } \\
\hline & [41] & {$[7]$} & SSM & FIM \\
\hline$\overline{\mathrm{CN}^{-}}$ & - & - & 0.2 & -3.2 \\
\hline $\mathrm{Cl}^{-}$ & -1.4 & -2.9 & 2.5 & -1.8 \\
\hline $\mathrm{I}^{-}$ & - & -1.8 & 1.6 & -3 \\
\hline $\mathrm{SO}_{4}{ }^{2-}$ & -1.5 & -4.0 & -2.8 & -2.9 \\
\hline $\mathrm{C}_{2} \mathrm{O}_{4}{ }^{2-}$ & -1.4 & -2.1 & -0.2 & -3.2 \\
\hline $\mathrm{CO}_{3}{ }^{2-}$ & -1.6 & -2.6 & -1.3 & -3.1 \\
\hline $\mathrm{ClO}_{4}^{-}$ & -1.9 & -1.8 & -1.5 & -3.0 \\
\hline $\mathrm{NO}_{3}^{-}$ & -1.6 & -2.4 & -1.2 & -1.9 \\
\hline $\mathrm{Sal}^{\mathrm{a}}$ & - & -2.3 & -1.5 & -3.0 \\
\hline $\mathrm{OAc}^{-}$ & - & -3.2 & 1.8 & -2.3 \\
\hline D.L. (p Chromate) & 5.9 & 6 & & \\
\hline D.R. (p Chromate) & $1-5.3$ & $1-5.6$ & & \\
\hline Response time (s) & 13 & $20-25$ & & \\
\hline Stability (day) & 300 & 60 & & \\
\hline $\mathrm{pH}_{\text {range }}^{\mathrm{b}}$ & $6.5-10.0$ & $8.0-12.0$ & & \\
\hline Slope $\left(\mathrm{mV} \cdot\right.$ decade $\left.^{-1}\right)$ & -29.0 & -28.8 & & \\
\hline Conditioning time $(\mathrm{h})$ & - & - & & \\
\hline Standard deviation & 0.2 & 0.5 & & \\
\hline
\end{tabular}

${ }^{\text {a }}$ Salicylate.

${ }^{\mathrm{b}}$ The $\mathrm{pH}$ range of the electrode response is independent of $\mathrm{pH}$.

The EMF response of the electrode to different concentrations of chromate samples demonstrated a linear range from $5.0 \times 10^{-6}$ to $1.0 \times 10^{-2}\left(r^{2}=0.9954\right)$ (Figure 9). Inset of Figure 8 shows the linear segment of the response of the electrode. The slope of calibration curve was $29.4 \pm 0.3 \mathrm{mV}$ per decade of $\mathrm{CrO}_{4}{ }^{2-}$ concentration.

To study the effect of modification and also the effect of nanoparticles on the potentiometric behavior of the proposed electrode, the potentiometric responses of some different membranes containing PVC alone, PVC + nanoclinoptilolite (NCP), PVC + surfactant, PVC + SMZ-clinoptilolite (SMZ$\mathrm{CP}$ ), and the proposed modified electrode (SMZ-NCP), were studied and the obtained results are shown in Figure 10. As results show, the membranes containing the raw PVC, nanozeolite alone, and also surfactant alone do not show a Nernstian response towards chromate. Comparing the results confirms the active component in the membranes is SMZ. According to the results, both prepared SMZs using microand nano-sized clinoptilolite show a Nernstian response towards chromate. But the obtained linear rang decreased when surfactant modified micro-sized clinoptilolite was used $\left(2.0 \times 10^{-5}\right.$ to $5.0 \times 10^{-3}, r^{2}=0.9918$, slope $=30.36 \mathrm{mV}$ per decade).

The lower and higher detection limits were $2.0 \times 10^{-7}$ and $2.0 \times 10^{-2} \mathrm{~mol} \mathrm{~L}^{-1}$, respectively. The relative standard deviation (RSD) of a single electrode (within electrode variation) was also funded out $(n=10)$. The RSD was small (1.01\%); the good electrode repeatability indicates that the membrane is homogeneous.

The reproducibility of the potentiometric response of the optimized electrode was also investigated by measuring

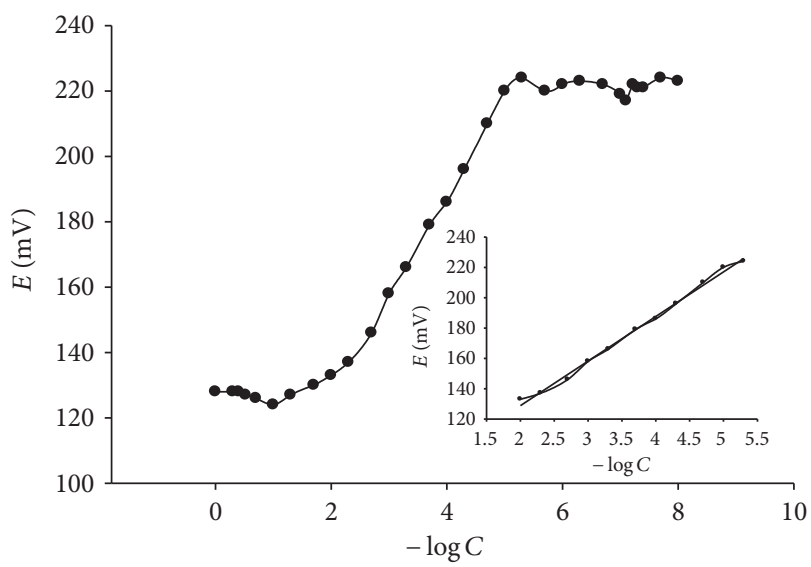

FIgURE 9: Potentiometric response of the proposed electrodes towards chromate ion (inset: linear segment (calibration curve) of the electrode response).

the response of five independent electrodes with the same composition. These measurements were also carried out in 4 replicates. The RSD (between electrode variations) was less than $2.5 \%$ (Table 8 ). The validity of the results was examined by " $g$ " value statistical testing, or a $g$-test [40], using the following equation:

$$
g=\operatorname{largest} \frac{s^{2}}{\left(s_{1}^{2}+s_{2}^{2}+s_{3}^{2}+s_{4}^{2}\right)},
$$

where $s_{i}^{2}$ is the variance of each class of determinations. The calculated $g$ value was 0.4261 , which is less than the critical 
TABLE 8: Potentiometric response of four independent optimized SMZ-PVC membrane electrodes.

\begin{tabular}{lccc}
\hline Electrode & Slope $=\bar{x}(n=5)\left(\mathrm{mV} \cdot\right.$ decade $\left.^{-1}\right)$ & $r^{2}$ & ${ }^{2}{ }^{a}$ \\
\hline 1 & $-29.9 \pm 0.5$ & 0.9903 & 1.7 \\
2 & $-29.3 \pm 0.4$ & 0.9841 & 1.4 \\
3 & $-29.3 \pm 0.7$ & 0.9900 & 2.4 \\
4 & $-29.3 \pm 0.5$ & 0.9883 & 1.7 \\
${ }^{\mathrm{a}}{ }^{2}{ }_{0.05,5,4}=0.6287[40]$. & & &
\end{tabular}

TABLE 9: Results of analysis of determination of chromate in electroplating waste water.

\begin{tabular}{lccc}
\hline No. & Method & $\operatorname{Cr}(\mathrm{VI})$ in molar determined $(n=6)$ & $t_{\text {exp }}{ }^{\mathrm{a}}$ \\
\hline 1 & Potentiometric method & $0.090 \pm 0.0006$ & 1.56 \\
2 & AAS method & $0.092 \pm 0.0008$ & \\
\hline
\end{tabular}

${ }^{\mathrm{a}} t_{0.05,10}=2.23[40]$.

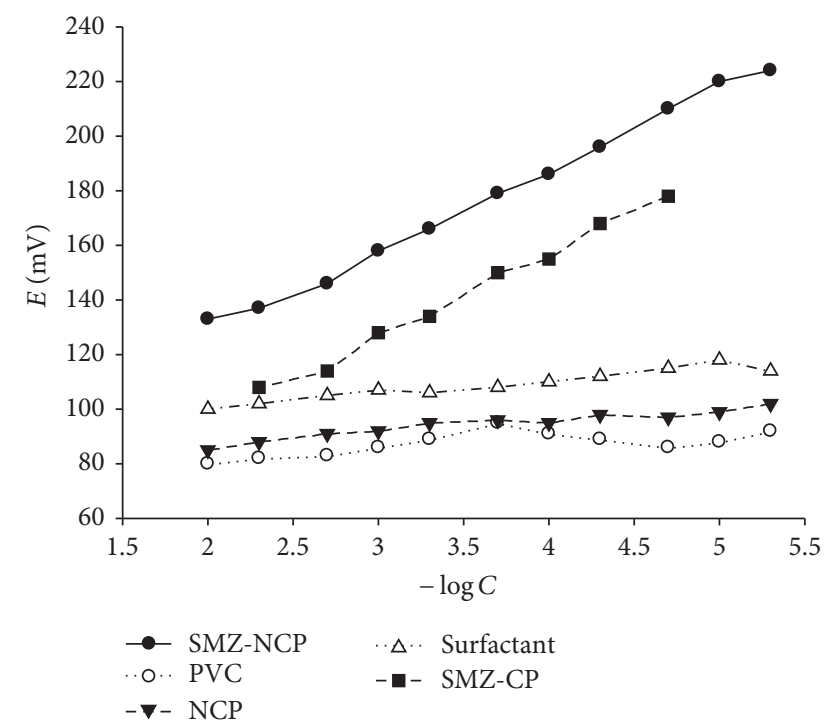

FIGURE 10: Potentiometric responses of some different membranes containing PVC, NCP, HDTMA surfactant, SMZ-CP, and SMZNCP towards chromate.

$g$ value at a $95 \%$ confidence interval $\left(g_{0.05,5,4}=0.6287,5\right.$ replicates per 4 classes) [40].

As shown in Table 7, the selectivity coefficient and dynamic linear range obtained for the proposed electrode are superior in some cases and comparable to those reported previously for other chromate-selective membrane electrodes based on a variety of different ionophores. Notably, in all cases in Table 7, response time, conditioning time, Nernstian behavior (slope values), and electrode response of the independent $\mathrm{pH}$ range for the proposed SMZ-PVC electrode are improved compared with other reported electrodes. Additionally, the short conditioning period of the proposed electrode saves time. The RSD values obtained from analyzing the reproducibility and repeatability of the SMZ-PVC electrode confirmed that the SMZ-PVC electrode has good precision.

\section{Analytical Application}

4.1. Analysis of Electroplating Waste. The proposed chromate sensor was also used for determining chromium (as chromate) in wastes discharged from electroplating industry. Sample from a local electroplating unit was collected, filtered, and stored without any further pretreatment. Suitable aliquots of sample solution were analyzed, after neutralizing with $\mathrm{NaOH}$ within $\mathrm{pH}$ range 7.0-8.0. The analyses were performed by direct potentiometry using calibration plot, and the results showed the chromate content in the wastewater obtained from measurement with the sensor was found to be in agreement with that determined by atomic absorption spectrometry (AAS) (Table 9).

4.2. Potentiometric Titration. The analytical applicability of the proposed sensor has been tested by using it as an indicator electrode to find out the end point in potentiometric titration of $\mathrm{CrO}_{4}{ }^{2-}$ with $\mathrm{Pb}^{2+} .10 \mathrm{~mL}$ of $1.0 \times 10^{-2} \mathrm{~mol} \mathrm{~L}^{-1} \mathrm{CrO}_{4}{ }^{2-}$ solution was brought to $\mathrm{pH} 8.0$ with $\mathrm{NaOH}$ and then titrated with $1.0 \times 10^{-2} \mathrm{~mol} \mathrm{~L}^{-1} \mathrm{~Pb}^{2+}$ solutions. Addition of $\mathrm{Pb}^{2+}$ to the solution precipitates $\mathrm{Pb}-\mathrm{CrO}_{4}$ which causes an increase in potentials as a result of decrease in the concentration of $\mathrm{CrO}_{4}{ }^{2-}$ in the solution. The end point obtained from the potentiometric curve is sharp and corresponds to the $1: 1$ stoichiometry of $\mathrm{Pb}^{2+}: \mathrm{CrO}_{4}{ }^{2-}$ (Figure 11). Inset of Figure 11 shows the first-derivation titration curve of electrode. Therefore, the sensor assembly can be successfully used as an indicator electrode.

\section{Conclusions}

The results of this work showed that the surfactant-modified zeolite when incorporated in polymeric matrix membrane preserved the anions adsorption manner. The amount of the modifier used in the membrane affected hydrophilicity and hydrophobicity properties definitely and this behavior will affect membrane response to different anions. According to this information the electrode with a composition 


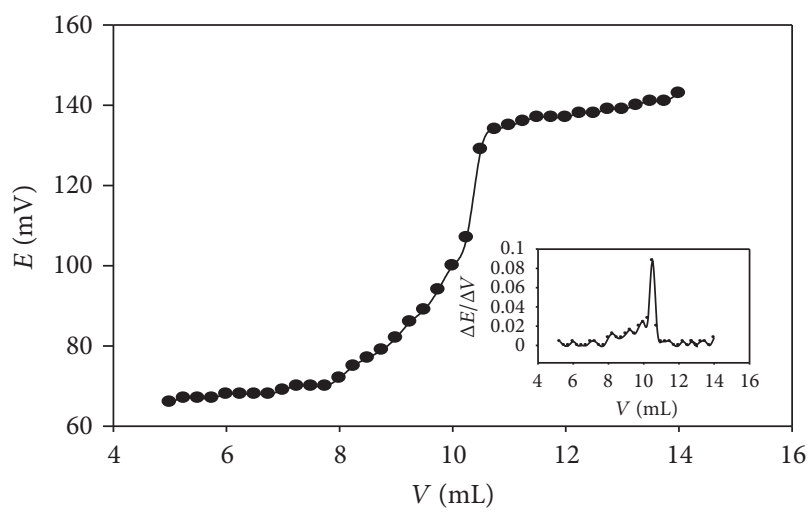

Figure 11: A potentiometric titration curve for $10 \mathrm{~mL}$ of a $0.01 \mathrm{~mol} \mathrm{~L}^{-1} \mathrm{CrO}_{4}{ }^{2-}$ solution with $0.01 \mathrm{~mol} \mathrm{~L}^{-1} \mathrm{~Pb}\left(\mathrm{NO}_{3}\right)_{2}$ using the proposed sensor as an indicator electrode at $25^{\circ} \mathrm{C}$ (inset: firstderivative curve, $\Delta E / \Delta V$ versus titrant volume).

SMZ:PVC:DOP in the ratio 4:32:64 made useful qualification for chromate potentiometric determination among anions such as benzoate, perchlorate, chlorate, oxalate, nitrate, iodide, and cyanide. The main advantage of the potentiometric sensor is its simplicity of preparation, short conditioning time, fast response time, Nernstian behavior, and improved good selectivity. The practical utility of membrane sensor was demonstrated by its use as an indicator electrode in the potentiometric titration of $\mathrm{CrO}_{4}{ }^{2-}$ with $\mathrm{Pb}^{2+}$ and was successfully applied to the determination of chromate in real samples.

\section{References}

[1] J. Koryta and K. Stulik, Ion Selective Electrodes, Cambridge University Press, Cambridge, UK, 1983.

[2] R. Oral, S. Meriç, E. D. Nicola, D. Petruzzelli, C. D. Rocca, and G. Pagano, "Multi-species toxicity evaluation of a chromiumbased leather tannery wastewater," Desalination, vol. 211, no. $1-3$, pp. 48-57, 2007.

[3] A. Mansri, K. I. Benabadji, J. Desbrières, and J. François, "Chromium removal using modified poly(4-vinylpyridinium) bentonite salts," Desalination, vol. 245, no. 1-3, pp. 95-107, 2009.

[4] A. Kortenkamp, M. Casadevall, S. P. Faux et al., "A role for molecular oxygen in the formation of DNA damage during the reduction of the carcinogen chromium(VI) by glutathione," Archives of Biochemistry and Biophysics, vol. 329, no. 2, pp. 199-207, 1996.

[5] D. Park, Y. S. Yun, D. S. Lee, and J. M. Park, “Optimum condition for the removal of $\mathrm{Cr}(\mathrm{VI})$ or total Cr using dried leaves of Pinus densiflora," Desalination, vol. 271, no. 1-3, pp. 309-314, 2011.

[6] S. S. M. Hassan, M. N. Abbas, and G. A. E. Moustafa, "Hydrogen chromate PVC matrix membrane sensor for potentiometric determination of chromium(III) and chromium(VI) ions," Talanta, vol. 43, no. 5, pp. 797-804, 1996.

[7] M. M. Ardakani, A. Dastanpour, and M. Salavati-Niasari, "Novel coated-wire membrane sensor based on bis(acetylacetonato) cadmium (II) for the determination of chromate ions," Microchimica Acta, vol. 150, no. 1, pp. 67-72, 2005.
[8] Y.-W. Choi, N. Minoura, and S. H. Moon, "Potentiometric $\mathrm{Cr}(\mathrm{VI})$ selective electrode based on novel ionophoreimmobilized PVC membranes," Talanta, vol. 66, no. 5, pp. 1254-1263, 2005.

[9] L. P. Singh, J. M. Bhatnagar, S. Tanaka, H. Tsue, and M. Mori, "Selective anion recognition: charged diaza crown ethers based electrochemical sensors for chromate ions," Analytica Chimica Acta, vol. 546, no. 2, pp. 199-205, 2005.

[10] S. S. M. Hassan, M. S. El-Shahawi, A. M. Othman, and M. A. Mosaad, "A potentiometric rhodamine-B based membrane sensor for the selective determination of chromium ions in wastewater," Analytical Sciences, vol. 21, no. 6, pp. 673-678, 2005.

[11] H. E. K. Ertürün, M. Yilmaz, and E. Kiliç, "Construction of an anion-selective electrode: dichromate-selective electrode," Sensors and Actuators B, vol. 127, no. 2, pp. 497-504, 2007.

[12] J. A. Smith and A. Galan, "Sorption of nonionic organic contaminants to single and dual organic cation bentonites from water," Environmental Science and Technology, vol. 29, no. 3, pp. 685-692, 1995.

[13] S. Xu and S. A. Boyd, "Cationic surfactant adsorption by swelling and nonswelling layer silicates," Langmuir, vol. 11, no. 7, pp. 2508-2514, 1995.

[14] G. M. Haggerty and R. S. Bowman, "Sorption of chromate and other inorganic anions by organo-zeolite," Environmental Science and Technology, vol. 28, no. 3, pp. 452-458, 1994.

[15] Z. Li, I. Anghel, and R. S. Bowman, "Sorption of oxyanions by surfactant-modified zeolite," Journal of Dispersion Science and Technology, vol. 19, no. 6-7, pp. 843-857, 1998.

[16] P. Chutia, S. Kato, T. Kojima, and S. Satokawa, "Adsorption of $\mathrm{As}(\mathrm{V})$ on surfactant-modified natural zeolites," Journal of Hazardous Materials, vol. 162, no. 1, pp. 204-211, 2009.

[17] N. Patdhanagul, T. Srithanratana, K. Rangsriwatananon, and S. Hengrasmee, "Ethylene adsorption on cationic surfactant modified zeolite NaY," Microporous and Mesoporous Materials, vol. 131, no. 1-3, pp. 97-102, 2010.

[18] A. Nezamzadeh and N. Masoudipour, "Application of a new potentiometric method for determination of phosphate based on a surfactant-modified zeolite carbon-paste electrode (SMZCPE)," Analytica Chimica Acta, vol. 658, no. 1, pp. 68-74, 2010.

[19] A. Nezamzadeh-Ejhieh and A. Esmaeilian, "Application of surfactant modified zeolite carbon paste electrode (SMZ-CPE) towards potentiometric determination of sulfate," Microporous and Mesoporous Materials, vol. 147, no. 1, pp. 302-309, 2012.

[20] A. Nezamzadeh-Ejhieh and Z. Nematollahi, "Surfactant modified zeolite carbon paste electrode (SMZ-CPE) as a nitrate selective electrode," Electrochimica Acta, vol. 56, no. 24, pp. 8334-8341, 2011.

[21] A. Nezamzadeh-Ejhieh and E. Mirzaeyan, "Oxalate membraneselective electrode based on surfactant-modified zeolite," Electrochimica Acta, vol. 56, no. 22, pp. 7749-7757, 2011.

[22] M. M. J. Treacy and J. B. Higgins, Collection of Simulated XRD Powder Patterns For Zeolites, Elsevier, Amsterdam, The Netherlands, 5th edition, 2007.

[23] G. M. Haggerty and R. S. Bowman, "Sorption of chromate and other inorganic anions by organo-zeolite," Environmental Science and Technology, vol. 28, no. 3, pp. 452-458, 1994.

[24] R. Malekian, J. Abedi-Koupai, and S. S. Eslamian, "Influences of clinoptilolite and surfactant-modified clinoptilolite zeolite on nitrate leaching and plant growth," Journal of Hazardous Materials, vol. 185, no. 2-3, pp. 970-976, 2011. 
[25] Z. Li and H. Hong, "Retardation of chromate through packed columns of surfactant-modified zeolite," Journal of Hazardous Materials, vol. 162, no. 2-3, pp. 1487-1493, 2009.

[26] J. Schick, P. Caullet, J. L. Paillaud, J. Patarin, and C. Mangold-Callarec, "Batch-wise nitrate removal from water on a surfactant-modified zeolite," Microporous and Mesoporous Materials, vol. 132, no. 3, pp. 395-400, 2010.

[27] J. Schick, P. Caullet, J. L. Paillaud, J. Patarin, and C. MangoldCallarec, "Nitrate sorption from water on a Surfactant-Modified Zeolite. Fixed-bed column experiments," Microporous and Mesoporous Materials, vol. 142, no. 2-3, pp. 549-556, 2011.

[28] Y. Zeng, H. Woo, G. Lee, and J. Park, "Adsorption of Cr(VI) on hexadecylpyridinium bromide (HDPB) modified natural zeolites," Microporous and Mesoporous Materials, vol. 130, no. 1-3, pp. 83-91, 2010.

[29] R. S. Bowman, "Applications of surfactant-modified zeolites to environmental remediation," Microporous and Mesoporous Materials, vol. 61, no. 1-3, pp. 43-56, 2003.

[30] R. S. Bowman, G. M. Haggerty, R. G. Huddleston, D. Neel, and M. M. Flynn, "Sorption of nonpolar organic compounds, inorganic cations, and inorganic oxyanions by surfactant-modified zeolites," in Surfactant-Enhanced Subsurface Remediation, D. A. Sabatini, R. C. Knox, and J. H. Harwell, Eds., vol. 594 of ACS Symposium Series, pp. 54-64, American Chemical Society, Washington, DC, USA, 1995.

[31] O. Ozdemir, M. Turan, A. Z. Turan, A. Faki, and A. B. Engin, "Feasibility analysis of color removal from textile dyeing wastewater in a fixed-bed column system by surfactantmodified zeolite (SMZ)," Journal of Hazardous Materials, vol. 166, no. 2-3, pp. 647-654, 2009.

[32] U. Wingenfelder, G. Furrer, and R. Schulin, "Sorption of antimonate by HDTMA-modified zeolite," Microporous and Mesoporous Materials, vol. 95, no. 1-3, pp. 265-271, 2006.

[33] E. J. Sullivan, D. B. Hunter, and R. S. Bowman, "Fourier transform Raman spectroscopy of sorbed HDTMA and the mechanism of chromate sorption to surfactant-modified clinoptilolite," Environmental Science and Technology, vol. 32, no. 13, pp. 1948-1955, 1998.

[34] S. Amemiya, P. Bühlmann, E. Pretsch, B. Rusterholz, and Y. Umezawa, "Cationic or anionic sites? Selectivity optimization of ion-selective electrodes based on charged ionophores," Analytical Chemistry, vol. 72, no. 7, pp. 1618-1631, 2000.

[35] E. Bakker, P. Bühlmann, and E. Pretsch, "Carrier-based ionselective electrodes and bulk optodes. 1. General characteristics," Chemical Reviews, vol. 97, no. 8, pp. 3083-3132, 1997.

[36] N. Kabay, M. Arda, B. Saha, and M. Streat, "Removal of Cr(VI) by solvent impregnated resins (SIR) containing aliquat 336," Reactive and Functional Polymers, vol. 54, no. 1-3, pp. 103-115, 2003.

[37] A. Bhowal and S. Datta, "Studies on transport mechanism of $\mathrm{Cr}(\mathrm{VI})$ extraction from an acidic solution using liquid surfactant membranes," Journal of Membrane Science, vol. 188, no. 1, pp. 1-8, 2001.

[38] M. E. Vallejo, F. Persin, C. Innocent, P. Sistat, and G. Pourcelly, "Electrotransport of $\mathrm{Cr}(\mathrm{VI})$ through an anion exchange membrane," Separation and Purification Technology, vol. 21, no. 1-2, pp. 61-69, 2000.

[39] D. W. Breck, Zeolite Molecular Sieves, John Wiley \& Sons, New York, NY, USA, 1974.

[40] R. L. Anderson, Practical Statistics for Analytical Chemists, D. Van Nostrand Reinhold Company, New York, NY, USA, 1987.
[41] A. K. Jain, V. K. Gupta, L. P. Singh, P. Srivastava, and J. R. Raisoni, "Anion recognition through novel C-thiophenecalix[4]resorcinarene: PVC based sensor for chromate ions," Talanta, vol. 65, no. 3, pp. 716-721, 2005.

[42] G. G. Guibault, R. A. Durst, M. S. Frant et al., "Recommendations for nomenclature of ion selective electrodes," Pure and Applied Chemistry, vol. 48, no. 1, pp. 127-132, 1976.

[43] Y. Umezawa, K. Umezawa, and H. Sato, "Selectivity coefficients for ion-selective electrodes: recommended methods for reporting $K_{\mathrm{A}, \mathrm{B}}^{\mathrm{pot}}$ pot values," Pure and Applied Chemistry, vol. 67, no. 3, pp. 507-518, 1995.

[44] E. Leontidis, "Hofmeister anion effects on surfactant selfassembly and the formation of mesoporous solids," Current Opinion in Colloid \& Interface Science, vol. 7, no. 1-2, pp. 81-91, 2002.

[45] U. Fiedler and J. Ruzicka, "Selectrode-the universal ionselective electrode: part VII. A valinomycin-based potassium electrode with nonporous polymer membrane and solid-state inner reference system," Analytica Chimica Acta, vol. 67, no. 1, pp. 179-193, 1973. 

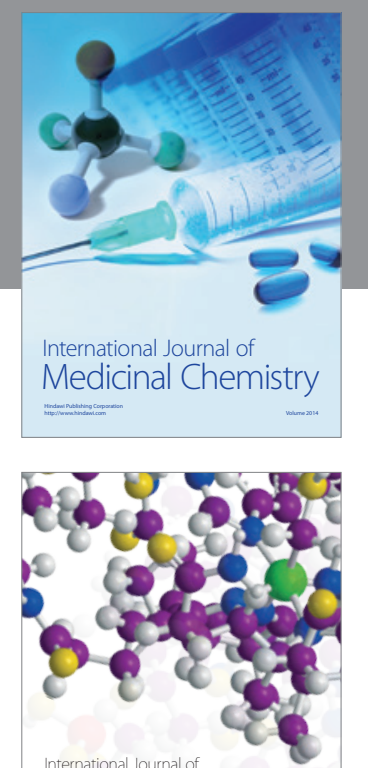

\section{Carbohydrate} Chemistry

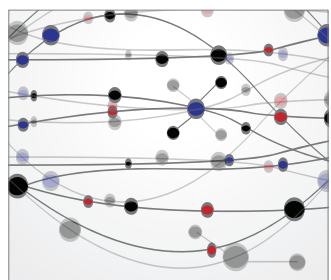

The Scientific World Journal
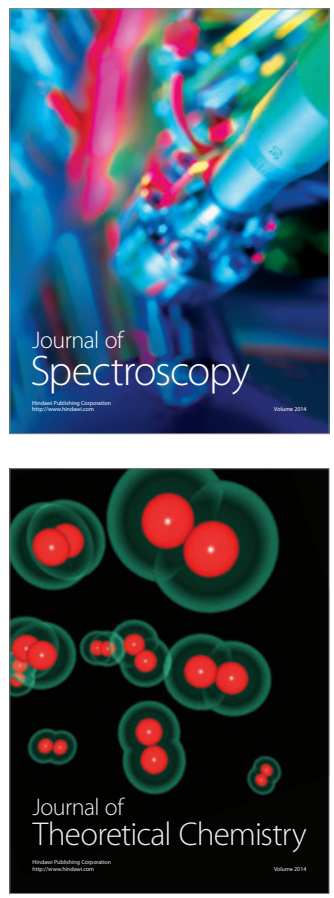
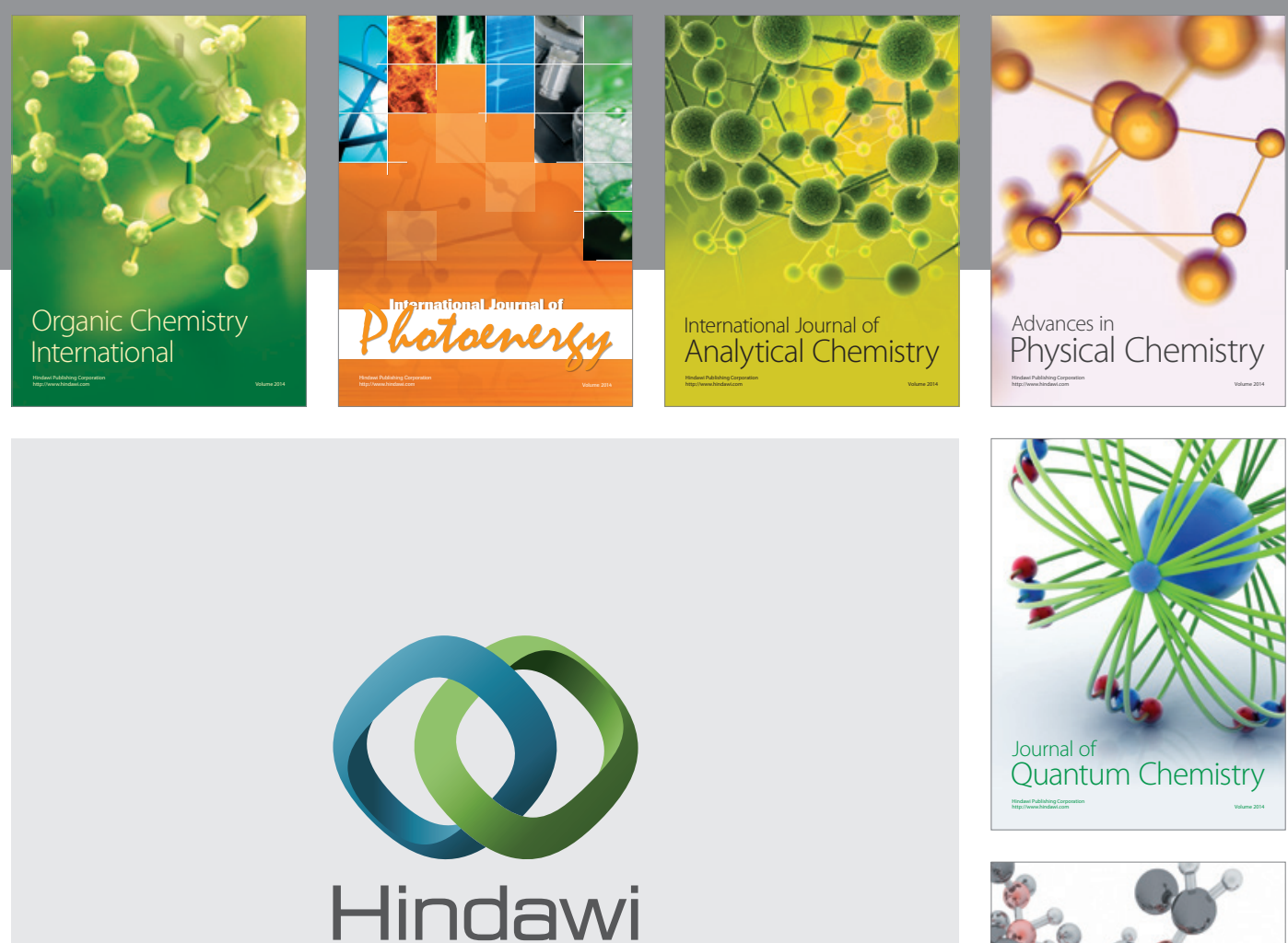

Submit your manuscripts at

http://www.hindawi.com

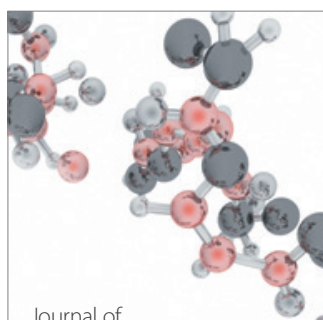

Analytical Methods

in Chemistry

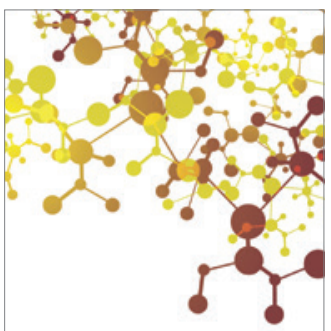

Journal of

Applied Chemistry

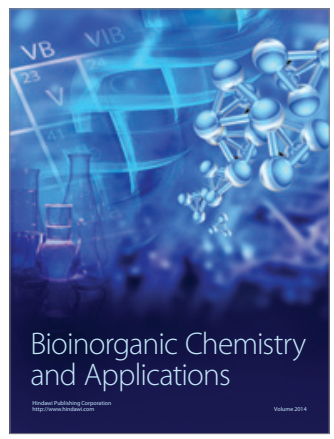

Inorganic Chemistry
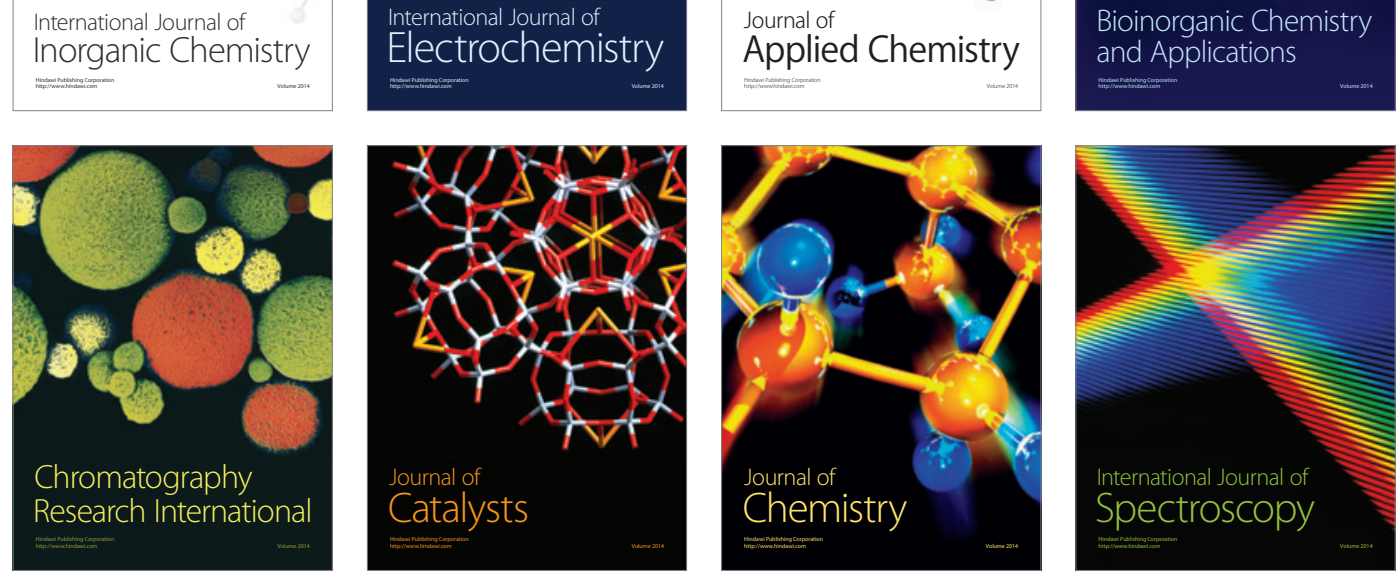